\title{
Post-Traumatic Peripheral Giant Osteoma in the Frontal Bone
}

\author{
Seong Hwan Kim, \\ Dong Seob Lim, \\ Do Hun Lee, \\ Kyung Pil Kim, \\ Jae Ha Hwang, \\ Kwang Seog Kim, \\ Sam Yong Lee
}

Department of Plastic and Reconstructive Surgery, Chonnam National University Medical School, Gwangju, Korea

\begin{abstract}
Osteomas are benign, slow-growing tumors that most frequently occur in the craniomaxillofacial region. These tumors are mostly asymptomatic and are generally found incidentally. A giant osteoma is generally considered to be greater than $30 \mathrm{~mm}$ in diameter or $110 \mathrm{~g}$ in weight. A 35-year-old female presented to us with complaints of a firm mass that showed continuous growth on the forehead following trauma. A hairline incision was made to expose the osteoma. Biopsy of the tumor confirmed a osteoma. There were no complications after surgery. Postoperative computed tomography revealed that the tumor was completely removed. Because a peripheral giant osteoma of the frontal bone with a history of trauma is a rare finding, thorough history-taking, physical examination, and preoperative imaging tests are needed for patients with a history of trauma to rule out a giant osteoma.
\end{abstract}

Keywords: Osteoma / Forehead / Frontal bone

\section{INTRODUCTION}

Osteomas are benign, slow-growing tumors that arise most frequently in the craniomaxillofacial region [1]. Characteristically, osteomas are non-tender and hard tumors that most commonly occur in the maxilla and the mandible [2]. They grow slowly and painlessly. The clinical signs depend on the size and location of the tumor, as well as the direction of its growth. Morphologically, they are similar to common osseous tissue. They are classified as central, peripheral, or extraskeletal. Central osteomas develop from the endosteum. Peripheral osteomas arise from the periosteum, and extraskeletal soft tissue osteomas grow within a muscle [3]. Treatment involves surgical intervention with a radical removal along the healthy bone $[4,5]$. Multiple etiologies are associated with the development of these tumors, including genetic disorders (Gardner syndrome), endocrine disorders, chronic

Correspondence: Jae Ha Hwang

Department of Plastic and Reconstructive Surgery, Chonnam National University Medical School, 42 Jebong-ro, Dong-gu, Gwangju 61469, Korea

E-mail: psjhhwang@daum.net

Received Sep 19, 2017 / Revised Oct 25, 2017 / Accepted Oct 26, 2017 inflammation, and trauma [6].

A giant osteoma is generally considered to be greater than 30 $\mathrm{mm}$ in diameter or $110 \mathrm{~g}$ in weight [7]. The authors report a rare case of a peripheral giant osteoma that developed on the frontal bone after an accident, along with a review of the literature.

\section{CASE REPORT}

A 35-year-old female presented to us with complaints of a firm mass that showed continuous growth on the forehead. It developed after a traumatic injury to the forehead 22 years ago (Fig. 1). The lesion was firm and non-tender. Preoperative computed tomography (CT) revealed a mass measuring $4.6 \mathrm{~cm} \times 4.0 \mathrm{~cm} \times 1.5 \mathrm{~cm}$ (volume of $27.6 \mathrm{~cm}^{3}$ ) with osseous density occupying the cortex of the frontal bone (Fig. 2). The volume had increased at a rate of $1.3 \mathrm{~cm}^{3}$ per year (2.1 mm per year).

A hairline incision was made to expose the osteoma (Fig. 3). The mass was larger than the incision line, and to effectively remove the mass, the tumor was divided by chisel and mallet. Histopathological findings revealed the mass was dense, compact 


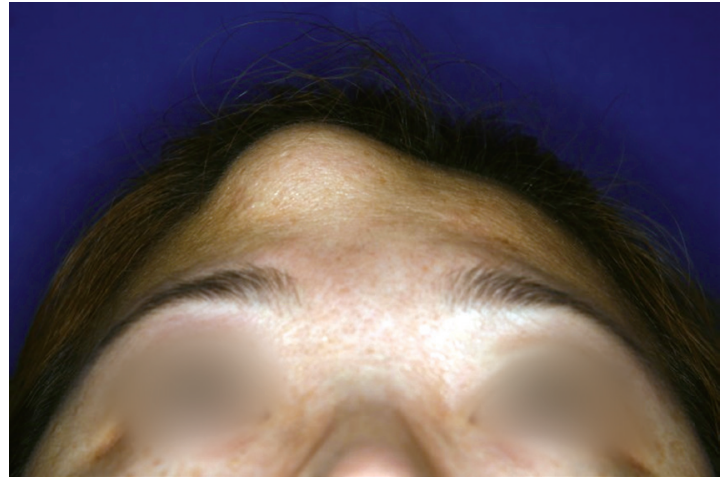

Fig. 1. Preoperative photograph of the giant osteoma on the forehead.
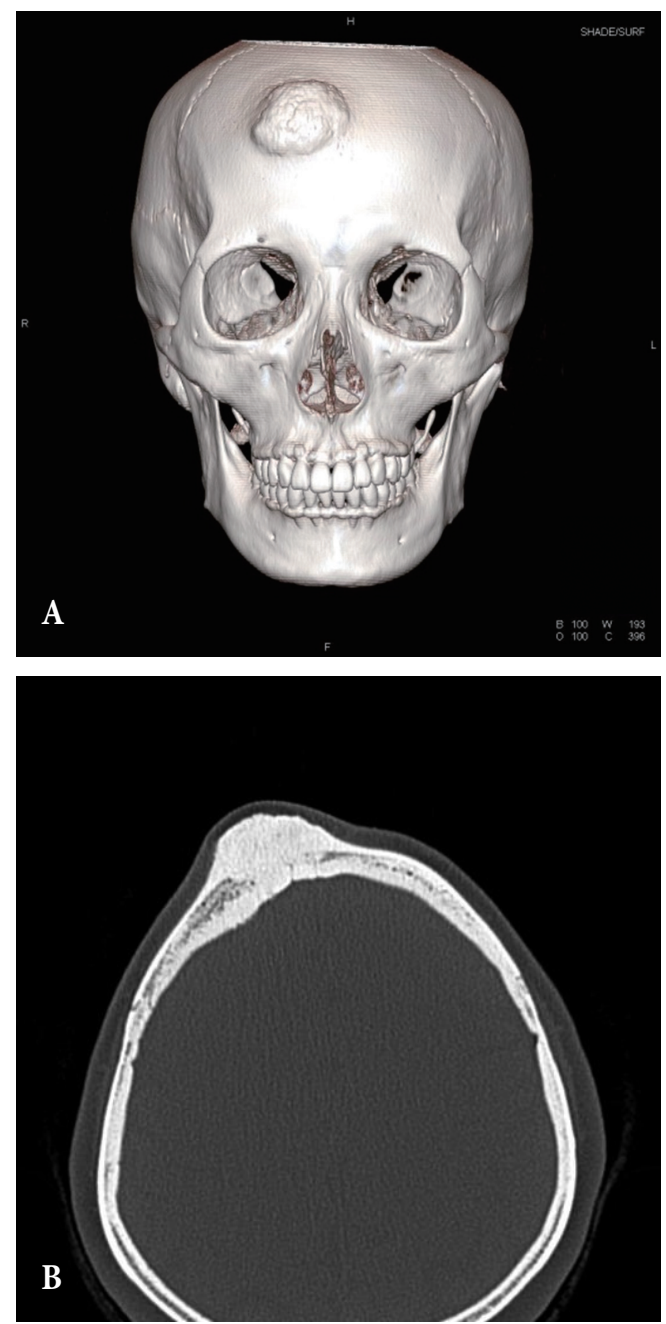

Fig. 2. Preoperative computed tomography image of the mass. A well-defined $4.6 \mathrm{~cm} \times 4.0 \mathrm{~cm} \times 1.5 \mathrm{~cm}$ radiopaque mass was observed. (A) Three dimensional image frontal view. (B) Axial view.

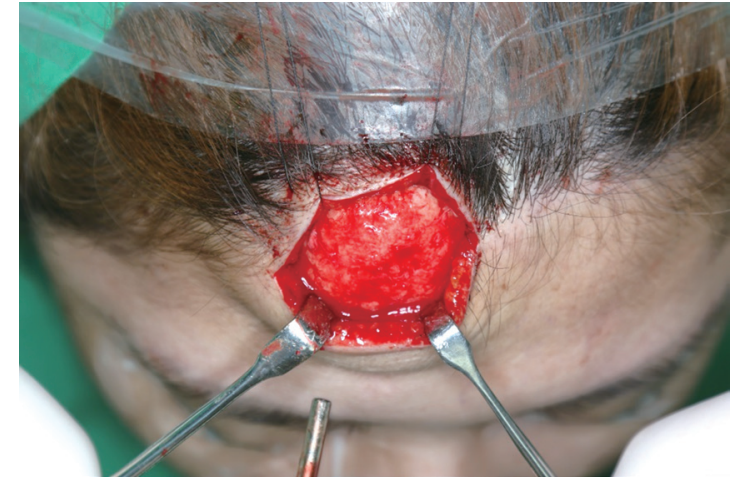

Fig. 3. Intraoperative photograph of the osteoma.
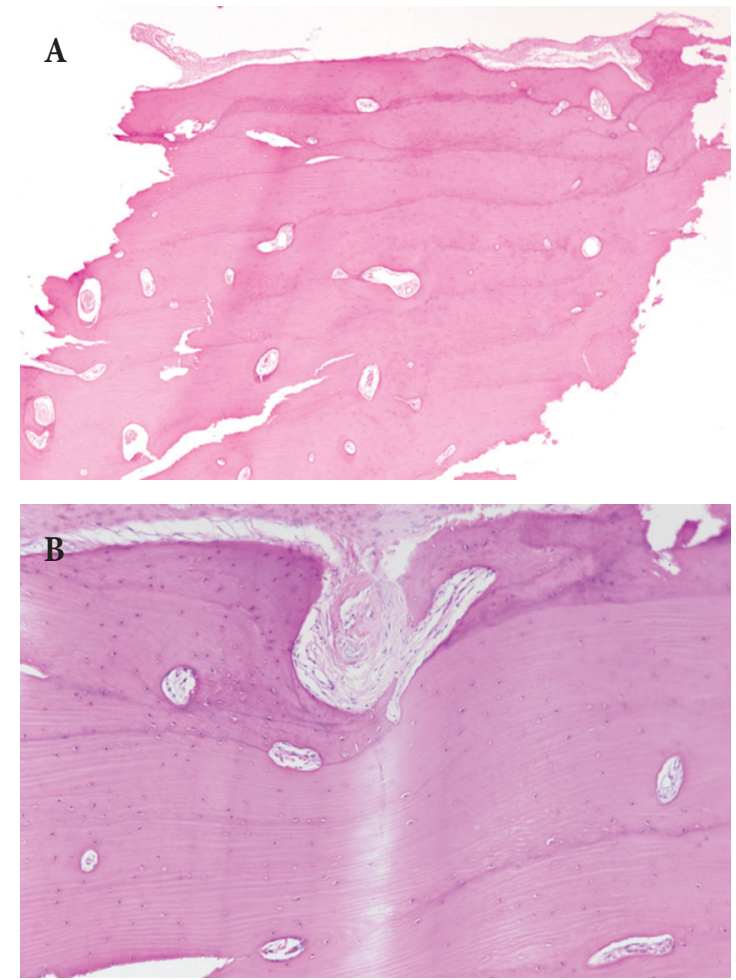

Fig. 4. Histopathological image of the mass. (A) H\&E, $\times 40$. (B) H\&E, $\times 100$.

bone and broad trabeculae of mature bone within paucicellular fibrous stroma and were suitable for findings of osteoma (Fig. 4). There were no complications after surgery. Postoperative CT revealed that the tumor was completely removed (Fig. 5). After 15 months of follow-up, the patient had no evidence of recurrence and was satisfied cosmetically. 


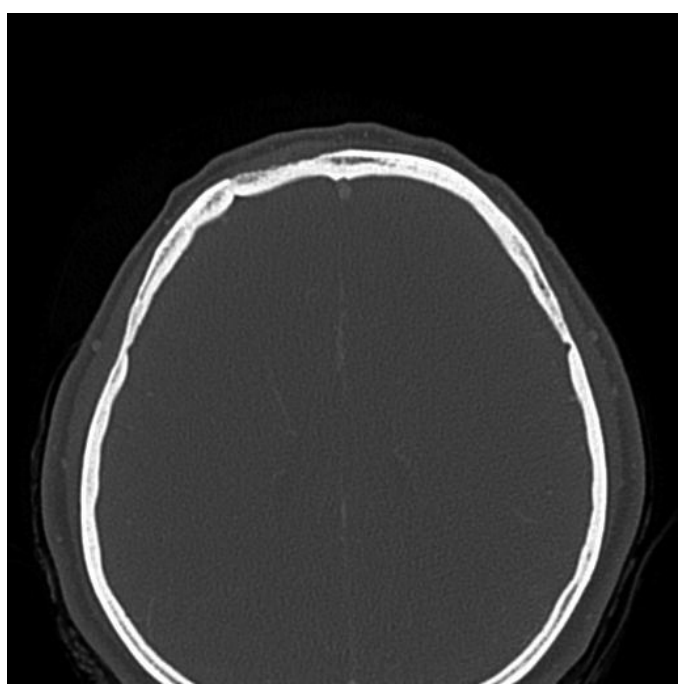

Fig. 5. Postoperative computed tomography image of the mass. The tumor was completely removed.

\section{DISCUSSION}

Osteomas are benign tumors consisting of osseous tissue that most frequently occur in the craniofacial area. The etiology of osteomas is multifactorial. In peripheral osteomas, a combination of trauma and muscle traction is a common cause. Subperiosteal bleeding from trauma combined with an elevated periosteum from the muscle traction force can cause an osteogenic reaction. The fact that most osteomas are small also implies that the pathogenesis of osteomas is due to a reactive process, rather than a neoplastic process [8-10].

The maxilla and mandible have been reported to be frequent sites of presentation, with varying rates of incidence [11]. Other studies revealed that frequent regions of development of osteoma were paranasal sinuses (especially frontal sinus) and the jaws $[12,13]$. The other study reported that the frontal bone was the most common site of presentation of peripheral osteomas, followed by the mandible and maxilla [8]. The gold standard for diagnosing osteomas and planning the therapeutic approach is CT. If the tumor extends into the intracranial area, magnetic resonance imaging is useful for delineating the extent of the tumor [14]. The bone is present as a compact area of internal homogeneous structures with well-defined margins that are devoid of en- hancement [15]. The patient in our case presented with a radiopaque mass lesion of the frontal bone in preoperative imaging. The differential diagnosis of this tumor includes fibrous dysplasia or ossifying fibroma. Furthermore, multiple osteomas presenting with intestinal polyposis suggests the diagnosis of Gardner syndrome [16]. Surgical management should be site- and size-specific. Endoscopic methods to remove the osteoma may be feasible for small osteomas located in the fronto-ethmoid region or at the mid-line of the frontal bone. Open surgery should be considered in large, complex frontal osteomas [17]. The patient in our case presented with a giant osteoma, and open surgery was performed through a hairline incision. Recurrence cases of peripheral osteoma after surgical excision are rarely reported. And no literatures are reported about malignant transformation of peripheral osteoma [18].

Although reports of a giant osteoma in the frontal sinus, ethmoidal sinus, or mandible have been published, a case of peripheral giant osteoma caused by trauma in the frontal bone is extremely rare $[1,7,10,11]$. Because a peripheral giant osteoma of the frontal bone with a history of trauma is a rare finding, thorough history-taking, physical examination, and preoperative imaging tests are needed for patients with post-traumatic huge masses to rule out a giant osteoma. This case also implies that an osteoma can increase in size. Small, asymptomatic osteomas probably do not need to be treated, but should be observed periodically. Therefore, the authors suggest that early excision, while the osteoma is small, will provide better cosmetic results. Further studies to examine the rate of growth of giant peripheral osteomas are necessary.

\section{CONFLICT OF INTEREST}

No potential conflict of interest relevant to this article was reported.

\section{PATIENT CONSENT}

The patient provided written informed consent for the publication and the use of their images. 


\section{REFERENCES}

1. Boffano P, Zavattero E, Roccia F, Ramieri G. Open surgical management of an asymptomatic giant frontal sinus osteoma. Craniomaxillofac Trauma Reconstr 2014;7:51-4.

2. Pohranychna K. A rare clinical case of the isolated primary frontal bone osteoma. Exp Oncol 2016;38:204-6.

3. Bodner L, Gatot A, Sion-Vardy N, Fliss DM. Peripheral osteoma of the mandibular ascending ramus. J Oral Maxillofac Surg 1998;56:1446-9.

4. Regezi JA, Sciubba JJ. Oral pathology: clinical pathologic correlations. Philadelphia: W.B. Saunders; 1999.

5. White SC, Pharoah MJ. Oral radiology: principles and interpretation. St. Louis: Mosby/Elsevier; 2009

6. Herford AS, Stoffella E, Tandon R. Osteomas involving the facial skeleton: a report of 2 cases and review of the literature. Oral Surg Oral Med Oral Pathol Oral Radiol 2013;115:el-6.

7. Cheng KJ, Wang SQ, Lin L. Giant osteomas of the ethmoid and frontal sinuses: Clinical characteristics and review of the literature. Oncol Lett 2013;5:1724-30.

8. Sayan NB, Ucok C, Karasu HA, Gunhan O. Peripheral osteoma of the oral and maxillofacial region: a study of 35 new cases. J Oral Maxillofac Surg 2002;60:1299-301.

9. Cutilli BJ, Quinn PD. Traumatically induced peripheral osteoma: report of a case. Oral Surg Oral Med Oral Pathol 1992;73:667-9.

10. Kaplan I, Calderon S, Buchner A. Peripheral osteoma of the mandible: a study of 10 new cases and analysis of the literature. J Oral Maxillofac Surg 1994;52:467-70.

11. Ohashi Y, Kumagai A, Matsumoto N, Izumisawa M, Hoshi H, Sugiyama Y. A huge osteoma of the mandible detected with head and neck computed tomography. Oral Sci Int 2015;12:31-6.

12. Larrea-Oyarbide N, Valmaseda-Castellon E, Berini-Aytes L, Gay-Escoda C. Osteomas of the craniofacial region: review of 106 cases. J Oral Pathol Med 2008;37:38-42.

13. Nah KS. Osteomas of the craniofacial region. Imaging Sci Dent 2011;41:107-13

14. Castelnuovo P, Valentini V, Giovannetti F, Bignami M, Cassoni A, Iannetti G. Osteomas of the maxillofacial district: endoscopic surgery versus open surgery. J Craniofac Surg 2008;19:1446-52.

15. DelBalso AM, Werning JT. The role of computed tomography in the evaluation of cemento-osseous lesions. Oral Surg Oral Med Oral Pathol 1986;62:354-7.

16. Boffano P, Bosco GF, Gerbino G. The surgical management of oral and maxillofacial manifestations of Gardner syndrome. J Oral Maxillofac Surg 2010;68:2549-54.

17. Vishwakarma R, Joseph ST, Patel KB, Sharma A. Giant frontal osteoma: case report with review of literature. Indian J Otolaryngol Head Neck Surg 2011;63:122-6.

18. Deliverska E. Peripheral osteoma of mandible: a case report and analysis of literature. J IMAB 2016;22:1274-8. 